\title{
TNF- $\alpha$ Gene G308A Polymorphism: Frequency in Patients with Type 2 Diabetes Mellitus
}

\section{Sanobarkhon Irgasheva ${ }^{1}$, Talat Saatov ${ }^{1}$, Elvira Ibragimova ${ }^{1}$, Khamid Karimov², Zafar Ibragimov ${ }^{1,2}$, Timur Alimov'2, Tokhir Ishanhodjaev ${ }^{1}$, Zulaykho Shamansurova, ${ }^{1,3}$, Bakhodyr Zainutdinov ${ }^{1}$, Mukhammadjon Mustafakulov ${ }^{1}$}

\begin{abstract}
'Laboratory of Metabolomics, Institute of Biophysics and Biochemistry at the National University of Uzbekistan Named after Mirzo Ulugbek, Tashkent, Uzbekistan; 'Department of Molecular Medicine and Cell Technologies, Scientific Research Institute of Hematology and Blood Transfusion, Ministry of Health of the Republic of Uzbekistan, Tashkent, Uzbekistan; ${ }^{3}$ Tashkent Pediatric Medical Institute, Tashkent, Republic of Uzbekistan.
\end{abstract}

\section{ABSTRACT}

Introduction: Tumour necrosis factor-alpha (TNF- $\alpha$ ), a pro-inflammation cytokine, plays a critical role in the pathogenesis of type 2 diabetes mellitus due to involving into the regulation of insulin signalling. Overproduction of this cytokine in metabolic syndrome is linked to TNF-a promoter gene G-308A polymorphism.

Objective: The work was initiated to measure the serum TNF- $\alpha$ concentrations and to determine the frequency of the Tumour necrosis factor-alpha (TNF- $\alpha$ ) gene G308A polymorphism in Uzbek patients with type 2 diabetes mellitus.

Methods: Healthy and type 2 diabetes mellitus Uzbek patients were observed.

Results: In the group with diabetes fasting blood glucose and the glycated haemoglobin (HbA1c) levels were 2.7 and 1.6 times higher respectively (both $\mathrm{p}<0.01$ ). HDL cholesterol was reduced, while LDL cholesterol, total cholesterol and triglycerides were higher in diabetic group. There was a significant difference between the serum TNF- $\alpha$ concentration in people with and without DM. As to TNF- $\alpha$ gene G308A polymorphism in the sample under study, it was represented mostly by GG homozygous genotype to be registered among persons without diabetes (90.2\%) and patients with type 2 DM (83.3\%). GA heterozygous genotype occurred in $9.8 \%$ and $16.7 \%$ of non-diabetics and diabetics, respectively. In our study, pathological AA homozygous genotype was found neither among the diabetics nor in the controls. There were no significant differences in frequencies of alleles and genotypes of TNFa gene G308A polymorphism. In the diabetics, frequencies of A allele and GA genotype is insignificantly higher than those in the controls.

Conclusion: In compare to non-diabetic controls, patients with type 2 diabetes mellitus had higher serum concentrations of TNF- $\alpha$. However, in that small group association of A allele and GA genotype of TNF- $\alpha$ gene with a higher risk of DM2 were insignificant.

Key Words: Type 2 diabetes mellitus, Cytokines, Tumour necrosis factor-alpha, TNF-a gene polymorphism

\section{INTRODUCTION}

Over the last few years, roles of cytokines in the pathogenesis of human diseases are being studied intensively. ${ }^{1,2}$ The Tumour necrosis factor-alpha (TNF- $\alpha$ ), a pro-inflammatory cytokine, is a highly active polyfunctional cytokine playing a key role in the pathogenesis of diseases such as Rheumatoid arthritis, Parkinson Disease, Obesity, Diabetes Mellitus (DM) and making an impact on the regulation of metabolism in a human organism. ${ }^{3}$
Under physiological conditions, TNF- $\alpha$ plays a critical role in the regulation of normal differentiation, growth and metabolism of various cells involved in mechanisms of cell death and apoptosis. On the other hand, TNF- $\alpha$ acts as a mediator of inflammation in various human diseases..$^{1,2}$ Findings from multiple studies demonstrated interrelation between increase in TNF- $\alpha$ levels and the initiation of inflammation and cancer, as well as of some metabolic, autoimmune and neurodegenerative diseases. ${ }^{2,5-7}$ There is convincing evidence of TNF- $\alpha$ as a key pro-inflammatory

\section{Corresponding Author:}

Sanobarkhon Irgasheva, Laboratory of Metabolomics, Institute of Biophysics and Biochemistry at the National University of Uzbekistan Named after Mirzo Ulugbek, Tashkent, Uzbekistan; Email: article_02@mail.ru

ISSN: 2231-2196 (Print)

Received: 15.07.2020
ISSN: $0975-5241$ (Online)

Revised: 03.08.2020
Accepted: 05.09.2020 
mediator involved in insulin resistance and type 2 diabetes mellitus pathogenesis. It is a trigger in obesity, diabetes mellitus and diabetic complications ${ }^{1,3}$

Intense production of TNF- $\alpha$ was found to correlate with G$308 \mathrm{~A}$ polymorphism in the promoter region of TNF- $\alpha$ gene. ${ }^{8}$ TNF $\alpha$ gene G308A polymorphism was demonstrated to govern the onset of hyperinsulinemia, arterial hypertension and obesity. ${ }^{9-11}$. Studies on TNF- $\alpha$ and its gene polymorphisms may be of predictive value in the estimation of risk of type 2 diabetes mellitus and its complications.

Our investigation aimed to determine the frequency of the Tumour necrosis factor-alpha (TNF- $\alpha$ ) gene G308A polymorphism in patients of Uzbek nationality with type 2 diabetes mellitus.

\section{MATERIALS AND METHODS}

We examined 48 Uzbek patients with type 2 diabetes mellitus of mean age $60.6 \pm 7.3$ years, $\mathrm{BMI}<30 \mathrm{~kg} / \mathrm{m}^{2}$ and mean disease duration 7.67 \pm 5.4 years. Forty-one people of Uzbek nationality, in average age $57.4 \pm 8.6$ without clinical and laboratory signs of carbohydrate metabolism disturbances were included in the control group. All participants were examined at the Republican Specialized Scientific-Practical Medical Centre of Endocrinology, Ministry of Health of the Republic of Uzbekistan. The glucose oxidase test was used to measure fasting capillary blood glucose employing kits from the "Cypress Diagnostics" (Belgium). An automatic analyzer DCA Vantage (Siemens, Germany) was used to measure HbA1c. Triglycerides, total cholesterol, as well as HDL cholesterol and LDL cholesterol were measured employing reagents provided by the Human GmbH (Germany) on a biochemical analyzer BA88A (Mindray Medical International Ltd, China). ELISA with test systems provided by Vektor-Best (Russian Federation) was used to measure the blood serum TNF- $\alpha$ concentrations by a microplate reader MR96 (Mindray Medical International Ltd, China) at 450 and $630 \mathrm{~nm}$.

A RIBO-Prep kit provided by AmpliSens (Russian Federation) was used to isolate DNA from the venous blood. The DNA concentration and purity was measured by a spectrophotometer NanoDrop 2000 (Thermo Fisher Scientific, USA). The first-stage PCR analysis with kits provided by Litech Research and Production Company (Russian Federation) was performed on the Rotor-Gene 6000, a PCR thermocycler (Corbett Research, Australia). G308A polymorphism (rs1800629) was genotyped by allele-specific PCR with kits provided by Litech Research and Production Company (Russian Federation). Amplification products were visualized in 3\% agarose gel stained with ethidium bromide under ultraviolet light.

To estimate associations of the TNF- $\alpha$ gene polymorphism with type 2 DM risk, the odds ratios (OR) were used for calculation as:

$$
\mathrm{OR}=(\mathbf{a x d}) /(\mathbf{b x c})
$$

where $\mathbf{a}$ is an allele (genotype) frequency in the sample of patients, $\mathbf{b}$ is an allele (genotype) frequency in the control sample, $\mathbf{c}$ is a sum of frequencies of other alleles (genotypes) in the sample of patients and $\mathbf{d}$ is a sum of frequencies of other alleles (genotypes) in the control sample. ORs were calculated in a $95 \%$ confidence interval (CI) and were compared by Hardy-Weinberg equilibrium. OR=1 was considered as the absence of any association, the $\mathrm{OR}>1$ quantifies positive association, that is, higher risk of the pathology, the $\mathrm{OR}<1$ quantifies negative association of an allele or a genotype, that is, lower risk of the pathology. "DoctorStat 2013, version 1.9" software package used for statistics. Data were accepted as significant at $\mathrm{p}<0.05$ and smaller according to the Student's distribution.

\section{RESULTS}

Biochemical parameters of peripheral blood from patients with type 2 diabetes mellitus and persons without diabetes shown in Table 1.

As it can be seen, in the group with diabetes fasting glucose and the glycated haemoglobin $(\mathrm{HbA} 1 \mathrm{c})$ were respectively 2.7 and 1.6 times higher (both $p<0.01$ ) than the parameters in persons without diabetes. In the diabetics, HDL cholesterol was found reduced by $22 \%(\mathrm{P}<0.05)$, concentrations of LDL cholesterol and total cholesterol were higher by $26 \%$ $(p<0.01)$ and $32 \%(p<0.05)$, respectively; triglycerides were 2.76 times higher $(\mathrm{P}<0.01)$ than in people without diabetes.

According to modern views, TNF- $\alpha$ inhibits the insulin-stimulated autophosphorylation of insulin receptors by tyrosine kinase in which it affects the insulin sensitivity, causes insulin resistance and abnormal glucose transport (Table 1).1,12

\begin{tabular}{|c|c|c|c|}
\hline Parameter & $\begin{array}{l}\text { Non-diabetic } \\
\text { persons }\end{array}$ & $\begin{array}{l}\text { Patients } \\
\text { with type } \\
2 \mathrm{DM}\end{array}$ & $\mathbf{P}$ \\
\hline $\begin{array}{l}\text { Fasting glucose, } \\
\mathrm{mmol} / \mathrm{l}\end{array}$ & $3.28 \pm 0.09$ & $8.9 \pm 0.4$ & $<0.01$ \\
\hline HbАıc, $\%$ & $5 \cdot 34 \pm 0.22$ & $8.56 \pm 0.39$ & $<0.01$ \\
\hline $\begin{array}{l}\text { Total cholesterol, } \\
\mathrm{mmol} / \mathrm{l}\end{array}$ & $4.25 \pm 0.13$ & $5.61 \pm 0.42$ & $<0.02$ \\
\hline Triglycerides, mmol/l & $1.12 \pm 0.24$ & $3.10 \pm 0.28$ & $<0.01$ \\
\hline $\begin{array}{l}\text { HDL cholesterol, } \\
\mathrm{mmol} / \mathrm{l}\end{array}$ & $1.19 \pm 0.10$ & $0.93 \pm 0.05$ & $<0.02$ \\
\hline $\begin{array}{l}\text { LDL cholesterol, } \\
\mathrm{mmol} / \text { л }\end{array}$ & $2.60 \pm 0.14$ & $3.28 \pm 0.18$ & $<0.01$ \\
\hline $\mathrm{TNF}-\alpha, \mathrm{pg} / \mathrm{ml}$ & $0.79 \pm 0.30$ & $5.81 \pm 0.43$ & $<0.01$ \\
\hline
\end{tabular}


In addition, TNF- $\alpha$ is known to reduce activity of lipoprotein lipase and its gene expression resulting in re-store of free fatty acids in the adipose tissue, thus preventing synthesis and uptake of triglycerides by adipocytes ${ }^{11}$. TNF- $\alpha$ has an impact on total cholesterol metabolism-enhancing its synthesis in the liver ${ }^{12}$. The changes in the concentrations of carbohydrates and lipids in the blood of patients with type $2 \mathrm{DM}$ might cause the increase in the concentrations of TNF- $\alpha$; this prompted us to determine TNF- $\alpha$ in peripheral blood of patients with type $2 \mathrm{DM}$.

There was a significant difference between the serum TNF- $\alpha$ concentrations in people with and without DM (5.81 \pm 0.43 versus $0.79 \pm 0.30 \mathrm{pg} / \mathrm{ml}$ ) (Table 1). It is consistent with the findings of others, demonstrated the elevated TNF- $\alpha$ concentrations in blood serum of patients with type $2 \mathrm{DM}^{13,14}$. In our study elevation of serum TNF- $\alpha$ concentrations in patients with type $2 \mathrm{DM}$ was shown related to abnormal carbohydrate and lipid metabolism (Figure 1).

Next, we studied frequencies of TNF- $\alpha$ gene G308A polymorphism in patients with type $2 \mathrm{DM}$. The genotype frequencies for the polymorphism in patients with and without type 2 DM presented in Figure 1.
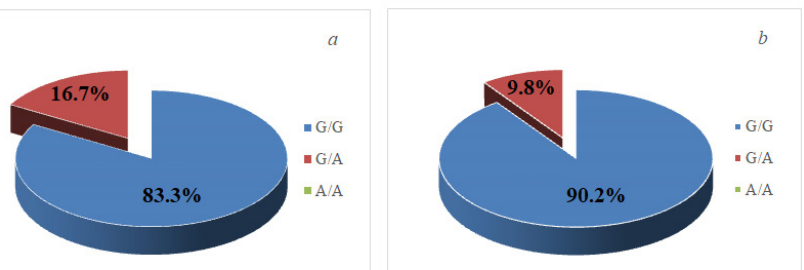

Figure 1: Frequencies of gene TNF- $\alpha$ G308A polymorphism genotypes in patients with type $2 \mathrm{DM}(\mathrm{a})$ and non-diabetics (b)

Our findings demonstrated that the genotype distribution for G308A polymorphic locus of the TNF- $\alpha$ gene in the diabetics and controls complies with Hardy-Weinberg equilibrium.

As to TNF- $\alpha$ gene G308A polymorphism in the sample under study, it was represented mostly by GG homozygous genotype to be registered among persons without diabetes $(90.2 \%)$ and patients with type $2 \mathrm{DM}(83.3 \%)$. GA heterozygous genotype occurred in $9.8 \%$ and $16.7 \%$ of non-diabetics and diabetics, respectively. In our study, pathological AA homozygous genotype was found neither among the diabetics nor in the controls.

As to allele frequencies, $\mathrm{G}$ and $\mathrm{A}$ alleles were found in $95.1 \%$ and $4.9 \%$, respectively, in persons without diabetes (Figure 2). In patients with type 2 diabetes mellitus, the values were $91.7 \%$ and $8.3 \%$, respectively; A allele occurred in the GA heterozygous variant. Thus, our findings demonstrate no significant differences ( $>0.05)$ in frequencies of alleles and genotypes of TNF $\alpha$ gene G308A polymorphism among non- diabetic controls and patients with type $2 \mathrm{DM}$. In the diabetics, frequencies of A allele and GA genotype $(8.3 \%$ and $16.7 \%$, respectively) is insignificantly higher than those in the controls (4.9\% and $9.8 \%$, respectively).

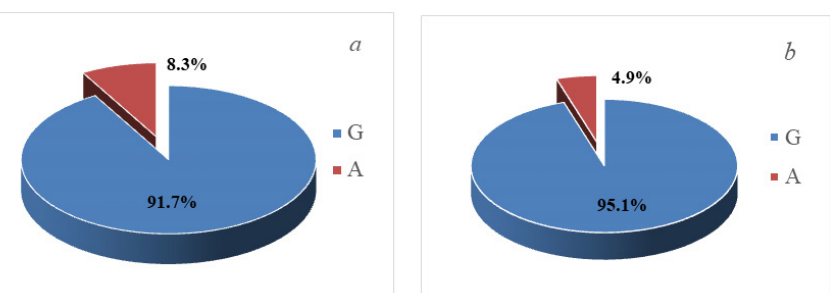

Figure 2: Frequencies of gene TNF- $\alpha$ G308A polymorphism alleles in patients with type $2 \mathrm{DM}(\mathrm{a})$ and the non-diabetics (b)

Our findings as per the distribution of genotypes and alleles for TNF- $\alpha$ gene G308A polymorphism are consistent with those from other studies in other ethnic groups ${ }^{15,16,17}$.

There was no statistically significant association of carriership of A allele $\left(\left(\chi^{2}=0,62 ; \mathrm{OR}=1,76 ; 95 \% \mathrm{CI}: 0,38-8,24\right)\right.$ and GA heterozygous genotype $\left(\chi^{2}=0.67\right.$; OR $=1.85 ; 95 \% \mathrm{CI}$ : $0,42-8,2)$ of TNF $\alpha$ gene G308A polymorphism with higher risk of type $2 \mathrm{DM}$.

In the controls, the data on $\mathrm{G}$ allele $\left(\left(\chi^{2}=0.62 ; \mathrm{OR}=0.56 ; 95 \%\right.\right.$ CI: $0.13-2.63)$ and GG genotype $\left(\chi^{2}=0.67 ; \mathrm{OR}=0.54 ; 95 \%\right.$ CI: 0.12-2.4) demonstrated their negative association with the disease, that is, $\mathrm{G}$ allele and GG genotype carriership in the control group was found protective and capable of reducing the risk of type $2 \mathrm{DM}$.

\section{DISCUSSION}

Type 2 diabetes mellitus is a multifactor disease resulting from the interaction between genetic and environmental factors. The genes determining the type 2 DM susceptibility exercise this interaction in cooperation with the genes underlying pathogenesis of obesity. Identification of polymorphic markers in the candidate genes products of which are involved in the pathogenesis of both obesity and type $2 \mathrm{DM}$ may be of predictive value in the estimation of the disease risk. TNF- $\alpha$ gene with a pro-inflammatory cytokine TNF- $\alpha$ as its product is considered as a candidate gene. ${ }^{11}$

TNF- $\alpha$ gene is located in the HLA III region on $6 \mathrm{p} 21$ chromosome. ${ }^{13} \mathrm{G} 308 \mathrm{~A}$ polymorphism is attributable to a mutation with the single nucleotide substitution of $\mathrm{G}$ with $\mathrm{A}$ at the position 308 in the TNF- $\alpha$ gene promoter region. Results from many studies demonstrated that the protein synthesis is accelerated in the carriers of the polymorphism resulting in the increased production of TNF- $\alpha .{ }^{11,14}$ Human TNF- $\alpha$ is a protein with the molecular mass of $17 \mathrm{kDa}$ produced by lymphocytes, monocytes and tissue macrophages in response 
to external extracellular stimulus. ${ }^{2,15}$ High concentrations of TNF- $\alpha$ blocks insulin signalling by phosphorylation of serine in the insulin receptor substrate 1 (IRS1) and induce insulin resistance in adipocytes and peripheral tissues resulting in abnormal biological effect of insulin and type 2 DM onset. ${ }^{1,15}$

There are literature data on the enhanced secretion of TNF- $\alpha$ by monocytes-macrophages in patients with type $2 \mathrm{DM}$ explaining high concentrations of TNF- $\alpha$ in the blood serum of patients. This may result in systemic inflammation, onset and progression of type $2 \mathrm{DM}$ complications. ${ }^{16}$ The higher level of TNF- $\alpha$ in the blood is identified at all stages of the inflammatory process. Its biological effects depend on its concentrations; elevation plasma of the cytokine in the blood is a specific marker for abnormal carbohydrate metabolism. High concentrations of TNF- $\alpha$ in blood plasma were established to be associated not only with insulin resistance but also with glucose intolerance ${ }^{8}$; a direct correlation between TNF- $\alpha$ concentration and both HbAlc and glucose was found $^{22}$. There is information about pro-atherogenic effects of TNF- $\alpha$, as well as about its involvement in lipid metabolism and atherogenic dislipidemia ${ }^{12}$. TNF- $\alpha$ was shown to determine concentrations of triglycerides in blood plasma promoting a reduction in HDL cholesterol and an elevation in LDL cholesterol. ${ }^{17,18}$

Several studies found increased concentrations of TNF- $\alpha$ in the blood of patients with type 2 DM.19-21 In our study, patients with type $2 \mathrm{DM}$ had significantly higher concentrations of the TNF- $\alpha$ than healthy controls. Our findings are consistent with other authors.5,10,21 The increase in concentrations of TNF- $\alpha$ in patients with type 2 DM may be associated with the onset and progression of disease complications. Thus, in persons with diabetic nephropathy TNF- $\alpha$ concentrations were higher than in patients with type $2 \mathrm{DM}$ without the complication suggesting higher inflammatory burden in those with diabetic nephropathy. 19

In several works the high risk of type $2 \mathrm{DM}$, especially in obese subjects were linked with TNF- $\alpha$ gene G308A polymorphism determining the onset of metabolic disorders, such as hyperinsulinemia, dyslipidemia, arterial hypertension, Polycystic ovarian syndrome..$^{22}$ Carriership of mutant $308 \mathrm{~A}$ allele of TNF- $\alpha$ is considered as a predictively unfavourable factor for impaired glucose tolerance, type $2 \mathrm{DM}$ and other clinical signs of insulin resistance syndrome. ${ }^{23,24}$

Several meta-analyses reflect findings from the studies on the association between TNF- $\alpha$ gene G308A polymorphism and type $2 \mathrm{DM}$ risk, ${ }^{25-27}$ though the conclusions are discrepant. The discrepancy can be attributed to ethnic peculiarities, sample sizes, variety of methods used for determination of the polymorphism, as well as to the non-uniformity of groups under study by age, sex and presence or absence of the disease risk factors.

\section{CONCLUSIONS}

Analysis of allelic and genotypic frequencies for G308A polymorphic locus of TNF- $\alpha$ gene in our sample of patients with type 2DM and healthy controls demonstrated the statistically insignificant association between carriership of A allele and GA heterozygous genotype of TNF $\alpha$ gene G308A polymorphism with a higher risk of type $2 \mathrm{DM}$. G allele and GG genotype were found protective and reducing the risk of type 2 DM. Thus, it was the first study shown the nonsignificant association between the polymorphism of the TNF $\alpha$ promoter region G308A and type 2 DM risk among patients of Uzbek nationality. Further studies are necessary to make clear the role of TNF $\alpha$ gene G308A polymorphism in type 2 $\mathrm{DM}$ in the ethnic group.

\section{ACKNOWLEDGMENT}

Authors acknowledge the immense help received from the scholars whose articles are cited and included in references to this manuscript. The authors are also grateful to authors / editors / publishers of all those articles, journals, and books from which the literature for this article has been reviewed and discussed.

\section{Conflict of Interest: Nil}

Funding: This study was done under the Funding of Ministry of Innovation of the Republic of Uzbekistan, Grant No П3-20170926405 "Development of a screening program for the early detection of genetically determined Diabetes Mellitus".

\section{Authors' contributions}

T. Saatov and Kh. Karimov provided a conception and design of the study.

S. Irgasheva , B. Zainutdinov and M. Mustafakulov dealt with the data and material collection.

S. Irgasheva, E. Ibragimova, Z. Ibragimov, T. Alimov, T. Ishanhodjaev and Z. Shamansurova performed material processing.

\section{Competing interests}

The authors have no competing interests to declare.

This study were done under the funding of Ministry of Innovation of the Republic of Uzbekistan, Grant No ПЗ20170926405 "Development of a screening program for the early detection of genetically determined Diabetes Mellitus"

\section{REFERENCES}

1. Hotamisligil GS. Inflammation and metabolic disorders. Nature 2006; 444: 860-867. 
2. Voronina EV, Lobanova NV, Yakhin R, Romanova NA. Role of Tumour necrosis factor-alpha in the immunopathogenesis of diseases of various etiologies and its role in the development of anti-cytokine therapy with antibodies. Meditsinskaya Immunologiya (Medical Immunology, Russia). 2018;20(6):797-806. (in Russian).

3. Mohammadi M, Gozashti MH, Aghadavood M, Mehdizadeh MR, Hayatbakhsh MM. Clinical Significance of Serum IL-6 and TNF- $\alpha$ Levels in Patients with Metabolic Syndrome. Rep Biochem Mol Bio 2017;6(1).

4. Tan P, Shamansurova Z, Bisotto S, Michel C, Gauthier MS, Rabasa-Lhoret R, et al. Impact of the prorenin/renin receptor on the development of obesity and associated cardiometabolic risk factors. Obesity (Silver Spring) 2014 Oct;22(10):2201-9.

5. Akash MH, Rehman K, Liquat A. Tumour Necrosis FactorAlpha: Role in Development of Insulin Resistance and Pathogenesis of Type 2 Diabetes Mellitus. J Cellular Biochem 2018; 119(1): 105-110.

6. Chen AI, Advani RH. Beyond the Guidelines in the Treatment of Peripheral T-cell Lymphoma: New Drug Development. J National Compreh Cancer Net 2008; 6(4): 428-435.

7. Cheng X, Yang L, He P, Li R, Shen Y. Differential activation of Tumour necrosis factor receptors distinguishes between brains from Alzheimer s disease and non-demented patients. J Alz Dis 2010; 19(2): 621-630.

8. Sookoian SC, González C, Pirola CJ. A meta-analysis on the G308A Tumour necrosis factor-alpha gene variant and phenotypes associated with the metabolic syndrome. Obesity Res 2005; 13(12): 2122-2131.

9. Dalziel B, Gosby AK, Richman RM. Association of the TNFalpha $-308 \mathrm{G} / \mathrm{A}$ promoter polymorphism with insulin resistance in obesity. Obes Res 2002;10(5): 401-407.

10. Kubaszek A, Pihlajamaki J, Komarovski V. Promoter polymorphisms of the TNF-alpha (G-308A) and IL-6 (C-174G) genes predict the conversion from impaired glucose tolerance to type 2 diabetes: the Finnish Diabetes Prevention Study. Diabetes 2003; 52(7): 1872-1876.

11. Nicaud V, Raoux S, Poirier O. The TNF-alpha -308 G/A polymorphism influences insulin sensitivity in offspring of patients with coronary heart disease: the European Atherosclerosis Research Study 2. Atherosclerosis 2000;161(2):317-325.

12. Hotamisligil GS, Budavari A. Murray DL and Spiegelman BM. The reduced tyrosine kinase activity of the insulin receptor in obesity-diabetes. The central role of Tumour necrosis factoralpha. J Clin Invest 1994; 4: 1543-1549.

13. Hajeer AH, Hutchinson IV. TNF-alpha gene polymorphism: clinical and biological implications. Microsc Res Tech 2000 Aug;50(3):216-28.

14. Kroeger KM, Carville KS, Abraham LJ. The -308 Tumour necrosis factor-alpha promoter polymorphism effects transcription. Mol Immunol 1997; 34(5): 391-399.
15. Shamansurova ZM, Saatov TS, Takhrirov LS. Tumour necrosis factor-alpha: Role in the development of obesity and diabetes mellitus. Asian J Biochem Genet Mol Bio. 2020; 4(3): 29-42.

16. Mirzoeva LA, Nikiforov NG, Aladinskyi VA, Sobenin IA, Nedosugova LV, Orekhov AN. Elevation in the spontaneous and induced secretion of TNF- $\alpha$ by monocytes-macrophages in patients with type 2 diabetes mellitus. Problems of endocrinology (Problemy endocrinologii), 2014;60(5):22-25 (in Russian).

17. Skoog TW, Dichtl W, Boquist S, Skoglund-Andersson C. Plasma Tumour necrosis factor-alpha and early carotid atherosclerosis in healthy middle-aged men. Eup Heart J 2002; 23: 376-383.

18. Sookoian SC, González C, Pirola CJ. A meta-analysis on the G308A Tumour necrosis factor-alpha gene variant and phenotypes associated with the metabolic syndrome. Obesity Res 2005; 13(12): 2122-2131.

19. Navarro JF, Mora C, Gomez M, Muros, M, Lopez-Aguilar $\mathrm{C}$, Garcia J. Influence of renal involvement on peripheral blood mononuclear cell expression behaviour of tumour necrosis factor- $\alpha$ and interleukin- 6 in type 2 diabetic patients. Nephrol Dial Transplant 2008;23: 919-926.

20. Moriwaki Y, Yamamoto T, Shibutani Y, Aoki E, Tsutsumi Z, Takahashi S, et al. Elevated levels of interleukin-18 and Tumour necrosis factor-alpha in serum of patients with type 2 diabetes mellitus: relationship with diabetic nephropathy. Metabolism 2003;52; 605-608.

21. Chen YL, Qiao YC, Xu Y.Serum TNF- $\alpha$ concentrations in type 2 diabetes mellitus patients and diabetic nephropathy patients: A systematic review and meta-analysis. Immunol Lett 2017;186:52-58.

22. Mohammadi M, Gozashti MH, Aghadavood M, Mehdizadeh MR , Hayatbakhsh MM. Clinical Significance of Serum IL-6 and TNF- $\alpha$ Levels in Patients with Metabolic Syndrome. Rep Bioche Mol Bio 2017;6(1).

23. De Luis DA, Aller R, Izaola O. Allelic frequency of G308A polymorphism of Tumour necrosis factor alpha gene and relation with cardiovascular risk factors and adipocytokines in obese patients. Nutr Hospit 2011; 26(4): 711-715.

24. Golshani H, Haghani K, Dousti M, Bakhtiyari S. Association of TNF $\alpha 308 \mathrm{G} /$ A polymorphism with type 2 diabetes : A casecontrol study in the Iranian Kurdish ethnic group. Osong Public Health Res Perspect 2015; 6(2): 94-99.

25. Feng RN, Zhao C, Sun CH. A meta-analysis of TNF 308 G/A polymorphism and type 2 diabetes mellitus. PLOS ONE 2011; 6(4): e18480.

26. Zheng-hui Liu, Yuan-lin Ding, Ziang-Chaug Xiu, Hai-yan Pan, Yan Ziang, Shau -Quang Zhong, Wewli Liu, Shao-Qiang Rao, Dan-li Kong. A meta-analysis of the association between TNF-a $-308>$ A polymorphism and type 2 diabetes mellitus in the Han Chinese population. PLOS ONE, 2013; 8 (3): 1-6.

27. Zhao Y, Li L, Zang L, Zang Y, Yang Y, Tang Y, Fu. P The TNF- $\alpha$ $308 \mathrm{G} / \mathrm{A}$ polymorphism is associated with the 2 diabetes mellitus: an updated meta-analysis. Mol Biol Rep 2014; 42:73-83. 